\title{
A QUALIDADE DA EDUCAÇÃO: PERSPECTIVAS E DESAFIOS
}

\author{
Luiz Fernandes Dourado* \\ JoÃo Ferreira de Oliveira*
}

\begin{abstract}
RESUMO: O presente texto problematiza e analisa o conceito de qualidade da educação, considerando suas múltiplas significações e dimensōes. Para tanto, apresenta o horizonte teórico-conceitual da temática, desenvolve a perspectiva de uma escola de qualidade socialmente referenciada e apresenta dimensōes intra e extraescolares fundamentais para a construção de uma educação de qualidade para todos, no contexto histórico, político, econômico e cultural da educação brasileira.
\end{abstract}

Palavras-chave: Qualidade da educação. Educação básica. Dimensões intra e extraescolares.

EDUCATION QUALITY: PERSPECTIVES AND CHALLENGES

ABSTRACT: This text discusses and analyses the concept of education quality considering its multiple meanings and dimensions. To do so, it presents the theoretical and conceptual horizon of the theme, develops the perspective of a socially referred quality school and presents the intra and extra-school fundamental dimensions required to build quality education for all in the historical, politic, economic and cultural context of Brazilian education.

Key words: Education quality. Basic education. Intra and extra-school dimensions.

* Doutor em Educação e professor titular da Faculdade de Educação da Universidade Federal de Goiás (UFG).E-mail: douradol@terra.com.br

** Doutor em Educação e professor adjunto da Faculdade de Educação da UFG.

E-mail: joaofo@terra.com.br 


\section{Introdução}

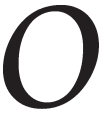

delineamento e a explicitação de dimensões, fatores e indicadores de qualidade da educação e da escola têm ganhado importância, mesmo que, em alguns casos, como mera retórica, na agenda de governos, movimentos sociais, pais, estudantes e pesquisadores do campo da educação. Nessa direção, no caso brasileiro, ressalta-se que a efetivação de uma escola de qualidade se apresenta como um complexo e grande desafio. No Brasil, nas últimas décadas, registram-se avanços em termos de acesso e cobertura, sobretudo no caso do ensino fundamental. Tal processo carece, contudo, de melhoria no tocante a uma aprendizagem mais efetiva.

Debater tais questōes remete à apreensão de um conjunto de determinantes que interferem, nesse processo, no âmbito das relaçōes sociais mais amplas, envolvendo questôes macroestruturais, como concentração de renda, desigualdade social, educação como direito, entre outras. Envolve, igualmente, questôes concernentes à análise de sistemas e unidades escolares, bem como ao processo de organização e gestão do trabalho escolar, que implica questóes como condiçôes de trabalho, processos de gestão da escola, dinâmica curricular, formação e profissionalização docente. Em outras palavras, é fundamental ressaltar que a educação se articula a diferentes dimensões e espaços da vida social sendo, ela própria, elemento constitutivo e constituinte das relações sociais mais amplas. A educação, portanto, é perpassada pelos limites e possibilidades da dinâmica pedagógica, econômica, social, cultural e política de uma dada sociedade.

Objetivando contribuir para a construção de referências analíticas para a qualidade da educação, o presente texto visa problematizar as múltiplas significações e conceitos relativos à qualidade da educação, bem como indicar dimensóes intra e extraescolares que interagem na consecução desse conceito. Compreende-se então a qualidade com base em uma perspectiva polissêmica, em que a concepção de mundo, de sociedade e de educação evidencia e define os elementos para qualificar, avaliar e precisar a natureza, as propriedades e os atributos desejáveis de um processo educativo de qualidade social. De outro lado, o texto ressalta que as finalidades educativas e, portanto, o alcance do que se almeja como qualidade da educação se vinculam aos diferentes espaços, atores e processos formativos, em seus diferentes níveis, ciclos e 
modalidades educativas, bem como à trajetória histórico-cultural e ao projeto de nação que, ao estabelecer diretrizes e bases para o seu sistema educacional, indica o horizonte jurídico normativo em que a educação se efetiva ou não como direito social.

\section{Qualidade da educação ou da escola: situando o horizonte analítico}

A discussão acerca da qualidade da educação remete à definição do que se entende por educação. Para alguns, ela se restringe às diferentes etapas de escolarização que se apresentam de modo sistemático por meio do sistema escolar. Para outros, a educação deve ser entendida como espaço múltiplo, que compreende diferentes atores, espaços e dinâmicas formativas, efetivado por meio de processos sistemáticos e assistemáticos. Tal concepção vislumbra as possibilidades e os limites interpostos a essa prática e sua relação de subordinação aos macroprocessos sociais e políticos delineados pelas formas de sociabilidade vigentes. Nessa direção, a educação é entendida como elemento constitutivo e constituinte das relações sociais mais amplas, contribuindo, contraditoriamente, desse modo, para a transformação e a manutenção dessas relações.

Com essa compreensão, este estudo situa a escola como espaço institucional de produção e de disseminação, de modo sistemático, do saber historicamente produzido pela humanidade. Assim, sem secundarizar a importância dos diferentes espaços e atores formativos (a família, o movimento social, a igreja, a mídia etc.), este artigo busca situar a discussão relativa à qualidade, tendo por norte pedagógico a função social da escola.

Que conceitos, representações ou concepções sinalizam uma escola de qualidade? Quais são os principais conceitos e definições que embasam os estudos, as práticas e as políticas educativas, bem como as dimensôes e os fatores que apontam a construção de uma educação de qualidade? É possível uma escola de qualidade para todos? Tais questões revelam a complexidade da temática da qualidade no campo educativo.

Nessa direção, um primeiro aspecto a ser ressaltado é que qualidade é um conceito histórico, que se altera no tempo e no espaço, ou seja, o alcance do referido conceito vincula-se às demandas e exigências 
sociais de um dado processo histórico. Caso se tome como referência o momento atual, tal perspectiva implica compreender que embates e visões de mundo se apresentam no cenário atual de reforma do Estado, de rediscussão dos marcos da educação -- como direito social e como mercadoria -, entre outros.

Outra questão fundamental consiste em identificar, no âmbito das políticas internacionais, quais são os compromissos assumidos pelos diferentes países na área da educação, como tais compromissos se configuram em políticas, programas e ações educacionais e como eles se materializam no cotidiano escolar. Por outro lado, é fundamental apreender quais são as políticas indutoras advindas dos referidos organismos multilaterais e que concepções balizam tais políticas. Para tanto, é fundamental problematizar a ênfase dada à teoria do capital humano, sobretudo pelo Banco Mundial, identificando o papel reservado à educação, bem como as diferentes feições assumidas por ela no que concerne à escola de qualidade.

No tocante à organização da educação nacional, sem perder de vista as injunções internacionais no campo, é importante compreender o papel dos sistemas e das escolas como espaços de regulação e de produção de uma dada dinâmica pedagógica, bem como o papel dos diferentes atores institucionais ou não do processo de construção das referidas regulações. ${ }^{1}$

Tais considerações sinalizam a apreensão de múltiplos fatores e regulaçóes (Dourado, 2007) que permeiam o que supostamente se entende por uma escola de qualidade.

Ao considerar o caso brasileiro, em que a oferta de escolarização se efetiva por meio dos entes federados (União, estado e municípios), com base na estruturação de sistemas educativos próprios, pode-se afirmar que tal processo vem se efetivando, historicamente, por intermédio do binômio descentralização e desconcentração das ações educativas. Esta constatação revela o quadro complexo, relativo ao estabelecimento de parâmetros de qualidade em um cenário desigual e combinado que caracteriza a educação brasileira. Este cenário é fortemente marcado por desigualdades regionais, estaduais, municipais e locais e por uma grande quantidade de redes e normas nem sempre articuladas. Nesse contexto, como avançar para a construção de indicadores comuns? Como assegurar educação de qualidade para todos? 
Tais questôes contribuem para deslindar o cenário complexo do quadro nacional e, ao mesmo tempo, permitem, com base em análise das políticas e programas governamentais, identificar a adoção histórica de uma determinada lógica político-pedagógica voltada para a ampliação das oportunidades educacionais, por meio da inclusão de etapas e modalidades educativas, sem fazer avançar, contudo, a adjetivação da qualidade pretendida.

Corroborando tal processo, vale destacar que os compromissos internacionais assumidos pelo Brasil, ${ }^{2}$ ao lado de outros chefes de Estado e de governo, buscam qualificar o tipo de educação a ser oferecido. No entanto, a temática da qualidade da educação ainda não se faz presente efetivamente nos diversos programas, projetos e ações governamentais.

Considerando esses compromissos, como assegurar educação inicial a todas as crianças, garantir a educação obrigatória e ampliar a oferta de educação secundária para $75 \%$ dos jovens (índice estabelecido para o atendimento desse nível de ensino), bem como oferecer oportunidades de educação continuada de qualidade a toda a população, em um país em que os indicadores educacionais revelam enormes disparidades?

Em análise anterior, Dourado, Oliveira e Santos (2007) apresentam reflexões acerca da qualidade da educação, com base na revisão de literatura relativa a temática, envolvendo o levantamento de estudos, avaliaçõoes e pesquisas ${ }^{3}$ e, ainda, a contribuição dos países membros das Cúpulas das Américas, com base em instrumento de coleta de dados produzido para esse fim. No referido estudo, os autores revelam que a qualidade da educação é um fenômeno complexo, abrangente, que envolve múltiplas dimensões, não podendo ser apreendido apenas por um reconhecimento da variedade e das quantidades mínimas de insumos indispensáveis ao desenvolvimento do processo de ensino-aprendizagem; nem, muito menos, pode ser apreendido sem tais insumos. Em outros termos, a qualidade da educação envolve dimensões extra e intraescolares e, nessa ótica, devem se considerar os diferentes atores, a dinâmica pedagógica, ou seja, os processos de ensino-aprendizagem, os currículos, as expectativas de aprendizagem, bem como os diferentes fatores extraescolares que interferem direta ou indiretamente nos resultados educativos.

Os autores ressaltam, ainda, com base em revisão bibliográfica de várias pesquisas, ${ }^{4}$ a importância de identificar quais são os elementos 
objetivos no entendimento do que vem a ser uma escola eficaz ou uma escola de qualidade, procurando compreender os custos básicos de manutenção e desenvolvimento. Por outro lado, indicam a importância de identificação das condições objetivas e subjetivas da organização e gestão escolar e da avaliação de qualidade da educação, por meio de processos de gestão, da dinâmica pedagógica e, consequentemente, do rendimento escolar dos estudantes. Nesse contexto, sinalizam que tais elementos podem, em parte, ser tratados como aspectos objetivos para a construção de condições de qualidade em uma escola considerada eficaz ou que produz resultados positivos. Ao mesmo tempo, alertam que, aliados aos aspectos objetivos, merecem destaque as características da gestão financeira, administrativa e pedagógica, os juízos de valor, as propriedades que explicitam a natureza do trabalho escolar, bem como a visão dos agentes escolares e da comunidade referente ao papel e às finalidades da escola e do trabalho nela desenvolvido.

Tais considerações ratificam a necessária priorização da educação como política pública, a ser efetivamente assegurada, o que implica: aumento dos recursos destinados à educação, regulamentação do regime de colaboração entre os entes federados, otimização e maior articulação entre as políticas e os diversos programas de ações na área; efetivação da gestão democrática dos sistemas e das escolas, consolidação de programas de formação inicial e continuada, articulados com a melhoria dos planos de carreira dos profissionais da educação etc.

Tendo como norte a perspectiva apontada, é importante desenvolver uma análise articulada dos diferentes aspectos que interferem no processo de construção de uma escola de qualidade, sem perder de vista a concepção de homem e de sociedade que se almeja construir.

A construção de uma escola de qualidade socialmente referenciada: dimensôes e desafios

A legislação brasileira no campo educacional, com destaque para a Lei de Diretrizes e Bases da Educação Nacional (LDB) e para o Plano Nacional da Educação (PNE), revela a importância da definição de padrôes de qualidade de ensino. ${ }^{5}$ Tal questão apresenta, contudo, dificuldades e diferenças significativas no que concerne à definição de um padrão único de qualidade, envolvendo questóes em termos de variedade 
e de quantidades mínimas, por aluno-ano, insumos indispensáveis ao processo de ensino e de aprendizagem, custo-aluno, relação aluno-professor etc.

Nesse sentido, sem sinalizar a adoção ou não de padrão único de qualidade, entende-se que é fundamental estabelecer a definição de dimensões, fatores e condições de qualidade a serem considerados como referência analítica e política no tocante à melhoria do processo educativo e, também, à consolidação de mecanismos de controle social da produção, à implantação e monitoramento de políticas educacionais e de seus resultados, visando produzir uma escola de qualidade socialmente referenciada.

Com essa compreensão, Darling-Hammond e Ascher (1991) ressaltam que as dimensões e fatores de qualidade da educação devem expressar relaçôes de: a) validade - entre os objetivos educacionais e os resultados escolares, não se reduzindo a médias ou similares; b) credibilidade - tendo em vista elementos que possam ser confiáveis em termos do universo escolar; c) incorruptibilidade - ou melhor, fatores que tenham menor margem de distorção; d) comparabilidade - ou seja, aspectos que permitam avaliar as condições da escola ao longo do tempo. A qualidade da educação, portanto, não se circunscreve a médias, em um dado momento, a um aspecto, mas configura-se como processo complexo e dinâmico, margeado por um conjunto de valores como credibilidade, comparabilidade, entre outros. Ratifica-se, portanto, que qualidade da educação é um conceito polissêmico e multifatorial, pois a definição e a compreensão teórico-conceitual e a análise da situação escolar não podem deixar de considerar as dimensóes extraescolares que permeiam tal temática.

Dourado, Oliveira e Santos (2007) traçam um importante cenário para a análise das dimensões intra e extraescolares. Inicialmente, definem o horizonte das dimensões extraescolares envolvendo dois níveis: o espaço social e as obrigações do Estado. O primeiro refere-se, sobretudo, à dimensão socioeconômica e cultural dos entes envolvidos (influência do acúmulo de capital econômico, social e cultural das famílias e dos estudantes no processo de ensino-aprendizagem); a necessidade do estabelecimento de políticas públicas e projetos escolares para o enfrentamento de questôes como fome, drogas, violência, sexualidade, famílias, raça e etnia, acesso à cultura, saúde etc.; a gestão e 
organização adequada da escola, visando lidar com a situação de heterogeneidade sociocultural dos estudantes; a consideração efetiva da trajetória e identidade individual e social dos estudantes, tendo em vista o seu desenvolvimento integral e, portanto, uma aprendizagem significativa; o estabelecimento de açôes e programas voltados para a dimensão econômica e cultural, bem como aos aspectos motivacionais que contribuem para a escolha e permanência dos estudantes no espaço escolar, assim como para o engajamento em um processo de ensinoaprendizagem exitoso. O segundo diz respeito à dimensão dos direitos dos cidadãos e das obrigações do Estado, cabendo a este último ampliar a obrigatoriedade da educação básica; definir e garantir padrões de qualidade, incluindo a igualdade de condiçôes para o acesso e permanência na escola; definir e efetivar diretrizes nacionais para os níveis, ciclos e modalidades de educação ou ensino; implementar sistema de avaliação voltado para subsidiar o processo de gestão educativa e para garantir a melhoria da aprendizagem; implementar programas suplementares, de acordo com as especificidades de cada estado e município, tais como: livro didático, merenda escolar, saúde do escolar, transporte escolar, recursos tecnológicos, segurança nas escolas.

Em seguida, os autores apresentam as dimensões intraescolares em quatro planos, destacando os elementos que devem compor cada uma delas.

O plano do sistema - condiçóes de oferta do ensino - refere-se à garantia de instalações gerais adequadas aos padrões de qualidade, definidos pelo sistema nacional de educação em consonância com a avaliação positiva dos usuários; ambiente escolar adequado à realização de atividades de ensino, lazer e recreação, práticas desportivas e culturais, reuniôes com a comunidade etc.; equipamentos em quantidade, qualidade e condições de uso adequadas às atividades escolares; biblioteca com espaço físico apropriado para leitura, consulta ao acervo, estudo individual e/ou em grupo, pesquisa on-line, entre outros; acervo com quantidade e qualidade para atender ao trabalho pedagógico e ao número de alunos existentes na escola; laboratórios de ensino, informática, brinquedoteca, entre outros, em condiçôes adequadas de uso; serviços de apoio e orientação aos estudantes; condições de acessibilidade e atendimento para portadores de necessidades especiais; ambiente escolar dotado de condições de segurança para alunos, professores, funcionários, 
pais e comunidade em geral; programas que contribuam para uma cultura de paz na escola; definição de custo-aluno anual adequado que assegure condições de oferta de ensino de qualidade.

O plano de escola - gestão e organização do trabalho escolar - trata da estrutura organizacional compatível com a finalidade do trabalho pedagógico; planejamento, monitoramento e avaliação dos programas e projetos; organização do trabalho escolar compatível com os objetivos educativos estabelecidos pela instituição, tendo em vista a garantia da aprendizagem dos alunos; mecanismos adequados de informação e de comunicação entre os todos os segmentos da escola; gestão democráticoparticipativa, incluindo condições administrativas, financeiras e pedagógicas; mecanismos de integração e de participação dos diferentes grupos e pessoas nas atividades e espaços escolares; perfil adequado do dirigente da escola, incluindo formação em nível superior, forma de provimento ao cargo e experiência; projeto pedagógico coletivo da escola que contemple os fins sociais e pedagógicos da escola, a atuação e autonomia escolar, as atividades pedagógicas e curriculares, os tempos e espaços de formação; disponibilidade de docentes na escola para todas as atividades curriculares; definição de programas curriculares relevantes aos diferentes níveis, ciclos e etapas do processo de aprendizagem; métodos pedagógicos apropriados ao desenvolvimento dos conteúdos; processos avaliativos voltados para a identificação, monitoramento e solução dos problemas de aprendizagem e para o desenvolvimento da instituição escolar; tecnologias educacionais e recursos pedagógicos apropriados ao processo de aprendizagem; planejamento e gestão coletiva do trabalho pedagógico; jornada escolar ampliada ou integrada, visando a garantia de espaços e tempos apropriados às atividades educativas; mecanismos de participação do aluno na escola; valoração adequada dos usuários no tocante aos serviços prestados pela escola.

O plano do professor - formação, profissionalização e ação pedagógi$c a$ - relaciona-se ao perfil docente: titulação/qualificação adequada ao exercício profissional; vínculo efetivo de trabalho; dedicação a uma só escola; formas de ingresso e condições de trabalho adequadas; valorização da experiência docente; progressão na carreira, por meio da qualificação permanente e outros requisitos; políticas de formação e valorização do pessoal docente: plano de carreira, incentivos, benefícios; definição da relação alunos/docente adequada ao nível, ciclo ou etapa de escolarização; 
garantia de carga horária para a realização de atividades de planejamento, estudo, reunióes pedagógicas, atendimento a pais etc.; ambiente profícuo ao estabelecimento de relações interpessoais que valorizem atitudes e práticas educativas, contribuindo para a motivação e solidariedade no trabalho; atenção/atendimento aos alunos no ambiente escolar.

O plano do aluno - acesso, permanência e desempenho escolar - refere-se ao acesso e condiçóes de permanência adequadas à diversidade socioeconômica e cultural e à garantia de desempenho satisfatório dos estudantes; consideração efetiva da visão de qualidade que os pais e estudantes têm da escola e que levam os estudantes a valorarem positivamente a escola, os colegas e os professores, bem como a aprendizagem e o modo como aprendem, engajando-se no processo educativo; processos avaliativos, centrados na melhoria das condiçôes de aprendizagem, que permitam a definição de padrões adequados de qualidade educativa e, portanto, focados no desenvolvimento dos estudantes; percepção positiva dos alunos quanto ao processo de ensino-aprendizagem, às condições educativas e à projeção de sucesso no tocante a trajetória acadêmico-profissional.

\section{Considerações finais}

À guisa de conclusão, destacam-se, a seguir, alguns aspectos fundamentais concernentes à construção de um movimento nacional em prol da qualidade da educação. Nesse sentido, entende-se que:

a) as dimensões, intra e extraescolares, devem ser consideradas de maneira articulada na efetivação de uma política educacional direcionada à garantia de escola de qualidade para todos, em todos os níveis e modalidades;

b) a construção de uma escola de qualidade deve considerar a dimensão socioeconômica e cultural, uma vez que o ato educativo escolar se dá em um contexto de posiçóes e disposiçóes no espaço social (de conformidade com o acúmulo de capital econômico, social e cultural dos sujeitos-usuários da escola), de heterogeneidade e pluralidade sociocultural, de problemas sociais que repercutem na escola, tais como fracasso escolar, desvalorização social dos segmentos menos favorecidos, incluindo a autoestima dos alunos etc.; 
c) a criação de condições, dimensões e fatores para a oferta de um ensino de qualidade social deve desenvolver-se em sintonia com ações direcionadas à superação da desigualdade socioeconômica-cultural presente nas regiōes;

d) o reconhecimento de que a qualidade da escola para todos, entendida como qualidade social, implica garantir a promoção e atualização histórico-cultural, em termos de formação sólida, crítica, ética e solidária, articulada com políticas públicas de inclusão e de resgate social;

e) os processos educativos e os resultados escolares, em termos de uma aprendizagem mais significativa, resultam de açóes concretas com o objetivo de democratização dos processos de organização e gestão, exigindo rediscussão das práticas curriculares, dos processos formativos, do planejamento pedagógico, dos processos de participação, da dinâmica da avaliação e, portanto, do sucesso escolar dos estudantes;

f) as relações entre alunos por turma, alunos por docente e alunos por funcionário são aspectos importantes das condiçóes da oferta de ensino de qualidade, uma vez que menores médias podem ser consideradas componentes relevantes para uma melhor qualidade do ensino oferecido;

g) o financiamento público é fundamental para o estabelecimento de condiçôes objetivas para a oferta de educação de qualidade e para a implementação de escolas públicas de qualidade, envolvendo estudos específicos relativos aos diferentes níveis, etapas e modalidades educativas;

h) a estrutura e as características da escola, em especial quanto aos projetos desenvolvidos, o ambiente educativo e/ou clima organizacional, o tipo e as condiçōes de gestão, a gestão da prática pedagógica, os espaços coletivos de decisão, o projeto político-pedagógico da escola, a participação e integração da comunidade escolar, a visão de qualidade dos agentes escolares, a avaliação da aprendizagem e do trabalho escolar realizado, a formação e condições de trabalho dos profissionais da escola, a dimensão do acesso, permanência e sucesso na escola, entre outros, são aspectos que traduzem positiva ou negativamente a qualidade da aprendizagem na escola; 
i) a qualidade do ambiente escolar e das instalaçóes também concorre para a definição de condições de oferta de ensino de qualidade;

j) os processos de organização e gestão da escola e escolha do diretor, sobretudo, no tocante aos processos de democratização, são fundamentais, haja vista que, em processos marcados por uma maior participação de professores, alunos, pais e funcionários, ocorre progressivo fortalecimento da autonomia e da democratização da escola; no caso de democratização da escolha do diretor, essa dinâmica, ao enfatizar processos de participação mais ampla e se articular com outros fatores, como formação inicial e continuada, além de experiência profissional, formação específica e capacidade de comunicação e de motivação dos diferentes segmentos da comunidade escolar, pode contribuir para a melhoria da qualidade de ensino;

1) associada à necessidade de uma sólida política de formação inicial e continuada, bem como à estruturação de planos de carreira compatíveis aos profissionais da educação, destaca-se a importância de políticas que estimulem fatores como motivação, satisfação com o trabalho e maior identificação com a escola como local de trabalho, como elementos fundamentais para a produção de uma escola de qualidade;

m) a satisfação e o engajamento ativo da comunidade escolar e, sobretudo, do estudante e do professor no processo político-pedagógico e, fundamentalmente, no processo de ensino-aprendizagem são fatores de fundamental importância para a melhoria do desempenho escolar e sucesso do estudante com qualidade na escola.

Recebido em novembro de 2007 e aprovado em agosto de 2008.

\section{Notas}

1. Segundo Barroso (2006, p. 13), o conceito de regulação, em que pesem os diferentes significados possíveis, pode ser utilizado "para descrever dois tipos de fenômeno diferenciados, mas interdependentes: os modos como são produzidas e aplicadas as regras que orientam a ação dos actores; os modos como esses mesmos atores se apropriam delas e as transformam". 
2. Os marcos do Plano de Ação em Educação, adotados por chefes de Estado e governo, apresentam as seguintes metas gerais: assegurar que, até o ano de 2010,100\% das crianças concluam a educação primária de qualidade e que, pelo menos, $75 \%$ dos jovens tenham acesso à educação secundária de qualidade, com percentagens cada vez maiores de jovens que terminem seus estudos secundários, e oferecer oportunidades de educação ao longo da vida à população em geral. Tais metas referem-se a uma Educação de Qualidade (Dourado, Oliveira \& Santos, 2007).

3. Ao longo do documento analítico, estabelece-se dialogo com vários estudos, avaliaçôes e pesquisas acerca da temática "qualidade da educação". É fundamental destacar que o referido documento apresenta indicações, dimensōes e concepçôes cuja base de dados foi efetivada pelo diálogo fecundo com referências nacionais e internacionais, com base na metodologia de análise documental que se assenta na busca de significações, recorrências e frequências temáticas, visando o estabelecimento de quadro analítico que transcenda os documentos analisados, em particular, e descortine outras possibilidades reflexivas de total responsabilidade dos autores.

4. Cf. Camargo (2006); Brasil/MEC/INEP (2003); Nóvoa (1999); UNESCO (2000, 2001, 2005).

5. A legislação de vários países estabelece como dever do Estado a definição de padrôes (mínimos) de qualidade.

\section{Referências}

AÇÃO EDUCATIVA; UNICEF; PNUD; MEC/INEP. Indicadores da qualidade na educação. São Paulo: Ação Educativa, 2004.

BANCO MUNDIAL. Estratégia do Banco Mundial para a educação na América Latina e no Caribe. 1999. Disponível em: <http:// www.bancomundial.org. Acesso em: 20 set. 2001.

BANCO MUNDIAL. Estratégia sectorial de educación. México, DF, 1999.

BARROSO, J. A investigação sobre a regulação das políticas públicas de educação em Portugal. In: BARroso, J. (Org.). A regulação das políticas públicas de educação: espaços, dinâmicas e atores. Lisboa: Educa, 2006. p. 9-39.

BRASIL. Lei n. 9.394, de 20 de dezembro de 1996. Dispóe sobre as Diretrizes e Bases da Educação Nacional. Diário Oficial da União, Brasília, DF, 23 dez. 1996.

BRASIL. Ministério da Educação. Instituto Nacional de Estudos e Pesquisas Anísio Teixeira (INEP). O desafio de uma educação de qualidade para todos: educação no Brasil - 1990-2000. Brasília, DF, 2003. 
A qualidade da educação: perspectivas e desafios

BRASIL. Ministério da Educação. Secretaria de Educação Básica (SEB). Plano de qualidade para a Educação Básica: diagnóstico e ações para elevar o nível de qualidade do ensino nas escolas brasileiras. Brasília, DF: $\mathrm{MEC} / \mathrm{SEB}, 2005$.

CAMARGO, R.B. et al. Pesquisa nacional qualidade na educação: problematização da qualidade em pesquisa de custo aluno-ano em escolas de educação básica. Brasília, DF: INEP, 2006.

COMISSÃO ECONOMICA PARA A AMERICA LATINA E CARIBE (CEPAL). Documento de 2000: equidad, desarrollo y ciudadanía. MéxiCO, DF, 2000.

DARLING-HAMMOND, L.; ASCHER, C. Creating accountability in big city schools. Urban Diversity Series, n. 102, 1991.

DOURADO, L.F.; OLIVEIRA, J.F.; SANTOS, C.A. A qualidade da educação: conceitos e definições. Série Documental: Textos para Discussão, Brasília, DF, v. 24, n. 22, p. 5-34, 2007.

DOURADO, L.F.; OLIVEIRA, J.F.; SANTOS, C.A. Políticas e gestão da educação básica no Brasil: limites e perspectivas. Educação \& Sociedade, Campinas, v. 28, n. 100, p. 921-946, 2007.

DOURADO, L.F.; PARO, V.H. Politicas educacionais e educação básica. São Paulo: Xamã, 2001.

DOURADO, L.F. et. al. Gestão escolar democrática. Goiânia: Alternativa, 2003.

ENGUITA, M.F. O discurso da qualidade e a qualidade do discurso. In: Gentili, P.; Silva, T. Neoliberalismo, qualidade total e educação: visões críticas. Petrópolis: Vozes, 1995. p. 93-110.

MATSUURA, K. Qualidade da educação: desafio do século 21. Notícias UNESCO, Brasília, DF, n. 25, set.-dez. 2004.

NOVOA, A. (Org.). As organizaçôes escolares em análise. Lisboa: Dom Quixote, 1999.

PARO, V.H. A gestão da educação ante as exigências de qualidade e produtividade da escola pública. In: Silva, L. (Org.). A escola cidadá no contexto da globalização. Petrópolis: Vozes, 1998. 
RIOS, T.A. Compreender e ensinar: por uma docência da melhor qualidade. 3. ed. São Paulo: Cortez, 2002.

UNESCO. Laboratório Latinoamericano de Evaluación de la Calidade de la Educación (LLECE). Primer estudio intenacional comparativo. Santiago de Chile, 1998.

UNESCO. Laboratório Latinoamericano de Evaluación de la Calidade de la Educación (LLECE). Primer estudio internacional comparativo, segundo informe. Santiago de Chile, 2000.

UNESCO. Laboratório Latinoamericano de Evaluación de la Calidade de la Educación (LLECE). Informe técnico. Santiago de Chile, 2001.

UNESCO. Laboratório Latinoamericano de Evaluación de la Calidad de la Educación (LLECE). Estudio cualitativo de escuelas con resultados destacables en siete paises latinoamericanos. Santiago de Chile, sept. 2002.

UNESCO. Cumbre de las Américas. Alcanzando las metas educativas. Informe Regional Proyecto Regional de Indicadores Educativos. Santiago de Chile, ago. de 2003. Disponível em: <http://www.prie.cl>. Acesso em: 10 maio 2005. 